\title{
Artelogie
}

artelogie Recherche sur les arts, le patrimoine et la littérature de l'Amérique latine

$6 \mid 2014$

Horizons et dispositifs des arts plastiques des pays du Río de la Plata (XXe siècle)

\section{Entre arte e linguagem: Xul Solar e a criação de um novo dispositivo literopictural em Latino América}

Nestor M. Habkost

\section{CpenEdition}

Journals

Edição electrónica

URL: http://journals.openedition.org/artelogie/1368

DOI: 10.4000/artelogie. 1368

ISSN: 2115-6395

Editora

Association ESCAL

Refêrencia eletrónica

Nestor M. Habkost, « Entre arte e linguagem: Xul Solar e a criação de um novo dispositivo literopictural em Latino América », Artelogie [Online], 6 | 2014, posto online no dia 24 junho 2014, consultado o 08 maio 2019. URL : http://journals.openedition.org/artelogie/1368; DOI : 10.4000/ artelogie.1368

Este documento foi criado de forma automática no dia 8 Maio 2019

Association ESCAL 


\title{
Entre arte e linguagem: Xul Solar e a criação de um novo dispositivo literopictural em Latino América
}

\author{
Nestor M. Habkost
}

\section{Entre arte e linguagem: Xul Solar e a criação de um novo dispositivo literopictural em Latino América}

1 As investigações que mobilizam a curiosidade de um homem e se explicitam no produzido devem-se, em grande medida, às condições socioculturais que circunscrevem e atravessam a existência. Recorrer a elas de maneira pontual permitirá expor e situar elementos presentes na origem do interesse do artista e pensador argentino Xul Solar (Oscar Agustín Alejandro Schulz Solari) pela construção de uma linguagem literopictórica com pretensão universal denominada de linguagem plasti-útil. Certamente marcaram a sensibilidade e estavam no horizonte do artista - nas décadas dedicadas a esta obra singular - as tensões e problemáticas implicadas nas dinâmicas político culturais que marcaram a arte Argentina e que fizeram com que alguns de seus mais importantes artistas não só focassem a pátria, trabalhando sobre temas e questões regionais $\mathrm{e}$ respondendo positivamente ou negativamente as tradições imperantes nos diversos campos de expressões artísticas, mas também as questões colocadas ou suscitadas pelas produções artísticas estrangeiras, especialmente a européia.

2 Xul Solar ocupa uma posição privilegiada neste contexto, seu nomadismo por territórios, línguas e culturas propiciou-lhe ângulos de abordagens sobre os caminhos da produção artística ocidental do início até a metade do século XX, levando-o a trabalhar na perspectiva da construção de duas línguas e de uma linguagem, sendo a última expressa numa obra plástica original sem precedentes no contexto europeu e americano. É pela via da arte e da linguagem que Oscar Agustín Alejandro Schulz Solari torna-se o inventor Xul Solar, o genial criador da linguagem plasti-útil. 
3 Nascido às $11 \mathrm{~h} 20$ do dia 14 de dezembro de 1887, na Província de Buenos Aires, filho de Emilio Schulz Riga (1865-1925), natural de Riga na Letônia e de Agustina Solari (1865-1959), nascida na cidade de Zoagli, Gênova, Itália, teve o artista desde cedo no núcleo familiar elementos provenientes de línguas e culturas distintas a formarem o seu espírito e a gestar possivelmente seus interesses pelas questões relacionadas à linguagem e à comunicação entre os homens. Do lado paterno aprendeu o alemão e do materno, o toscano e o xeneixe.

4 Seus pais eram imigrantes que vieram na leva de populações procedentes de diversos países europeus que aportaram nos países do continente americano a partir da segunda metade do século XIX. À época, buscava-se implementar o desenvolvimento econômico e social destes países através do estímulo à imigração de trabalhadores qualificados, especialmente para o setor industrial.

5 Na Argentina, a Constituição de 1853, em seu artigo 25, deixou explícitas as expectativas lançadas sobre os emigrantes europeus que, postos a serviço do país, iriam gerar uma mutação substancial no meio econômico e sociocultural:

El Gobierno Federal fomentará la inmigración europea; y no podrá restringir, limitar ni gravar con impuesto alguno la entrada en el territorio argentino de los extranjeros que traigan por objeto labrar la tierra, mejorar las industrias e introducir y enseñar las ciencias y las artes. (http://www.biblioteca.jus.gov.ar/co...)

O fluxo de europeus vindos para a Argentina é de importância considerável para compreender as mutações que irão ocorrer no interior da sociedade riopratense. Basta dizer que entre 1861 e 1870 o país recebeu cerca de 150.000 imigrantes e, entre 1881 e 1890, seu número chegou a casa dos 780.000 . Em 1910, época das comemorações do centenário da independência da Argentina, Buenos Aires, a Capital, contava com uma população superior a 1.200.000 habitantes, e o número de estrangeiros era maior que o de nativos argentinos.

7 Atraídos pela propaganda de um novo mundo e rápido progresso, os novos habitantes do país se inseriram em diversos ramos de atividades comerciais e industriais e mesmo no campo, impulsionando uma forte transformação econômica e social.

8 Trata-se de uma imigração de origem majoritariamente latina: os italianos, em maior número, vindos inicialmente do norte e mais tarde do sul da Itália, dedicaram-se à produção industrial e ao comércio e ocuparam lugar importante na vida econômica e social da Capital argentina. Um grande contingente de uma nova geração de espanhóis aportou mais tarde na terra que outrora foi dominada pelos reis de Espanha. Eles formaram o segundo grupo em grau de importância. Com recursos maiores que os italianos vieram fundamentalmente da Galícia, Astúrias, do País Basco, da Catalunha e de Castilha.

9 Os franceses, os ingleses, os alemães, os austro-húngaros, suíços e belgas vieram em número menor. Em geral com grau maior de qualificação profissional e de instrução, tiveram importante papel econômico no campo e na indústria.

10 Completaram o quadro os sírios, os libaneses, os russos e os armênios, tornando, a partir da introdução de suas línguas e religiões mais complexa a vida cultural argentina, principalmente a de Buenos Aires.

11 Os imigrantes traziam junto à esperança de mudança das suas condições de vida, traduzida em melhorias para alguns e enriquecimento para outros, os fortes traços de suas culturas de origem e a vibração peculiar de sua língua. 
12 Nos cafés, nas cantinas, nas lojas com produtos importados, nos bazares, nas casas de música, nos lugares públicos, gestos e dialetos diversos mesclavam-se forjando novos modos de expressão.

13 A Buenos Aires em que Xul Solar nasceu e cresceu era já uma cidade babélica mesclada de ambições e desalento; uma cidade atravessada por fluxos acelerados de misturas modernas e arcaísmos resistentes ; uma cidade que se tornava europeia em seus gostos, sua moda, sua arquitetura, enquanto a classe dirigente extraía do domínio territorial o fundamento do seu poder político e começava a considerar-se aristocrática e passava a falar de sua extirpe.

14 No plano político, a intensificação das lutas marcadas pela presença e liderança de grupos anarquistas e socialistas colocava cada vez mais em cheque as instâncias de poder estabelecidas. No plano político cultural, o temor das elites políticas em ver transpassarem ao domínio da cultura os conflitos sociais originados nas lutas pelo poder levou à promoção, através das instâncias oficiais, das expressões culturais ligadas às temáticas nacionais que tratavam quase exclusivamente do gaúcho, tipo social ligado à paisagem dos pampas em suas lidas com um modo de vida estritamente campeiro em oposição às novas formas de pensamento e de expressões artísticas que começavam a surgir.

15 No campo literário, bem poucos eram os escritores e poetas abertos às tendências modernas representadas por Rubén Darío. Leopoldo Lugones era um deles.

16 Na pintura imperava o academicismo, centrado em temáticas nacionais com forte resistência às tendências vanguardistas vindas da Europa. Florêncio Molina Campos, Carlos Ripamonte, Fernando Fader e Cesáreo Bernaldo de Quirós eram pintores que retratavam as tradições campestres, os hábitos, a indumentária e a iconografia de personagens crioulas.

17 Xul Solar viajou para a Europa em 1912, dois anos após a comemoração do centenário da independência argentina, e lá permaneceu até 1924.

18 Durante este período de doze anos, peregrinou por vários países, tendo permanecido maior tempo nas cidades de Londres, Paris, Turim, Zoagli, Munique e Stuttgart. Lá, o artista entrou em contato com os principais movimentos artísticos em cena na Europa, especialmente o expressionismo alemão e com personalidades ligadas ao campo místico, sendo esses os dois fatores que mais claramente se explicitarão nos traços constitutivos da sua obra, podendo esse ser chamado o seu período de iniciação.

19 No ano de chegada à Europa, Xul Solar adquiriu o almanaque Der Blaue Reiter (o Cavaleiro Azul) organizado por Wassily Kandinsky e Franz Marc, onde era apresentada a arte de vanguarda da época, marcando fortemente a sua vida. Percebeu que aquilo que buscava e já fazia na arte, não era um fato isolado, mas compartilhado por muitos artistas e isto lhe deu confiança ou certeza do caminho seguido. Dizia à respeito, em uma carta à sua mãe:

...estoy muy satisfecho porque veo cómo yo solo, sin ninguna inspiracion de afuera, he trabajado en la tendência que será la dominante del arte más elevado del porvenir... (BAUMGATNER, 1999, p. 29).

20 Através desse almanaque, Xul Solar penetrou no universo do expressionismo alemão. Os artistas do movimento Blaue Reiter não defendiam uma linguagem formal precisa por verem a arte como a materialização do espírito, não importando a forma que viesse a assumir. 0 mais importante na questão da forma, defendia Wassily Kandinsky, é se ela originou-se ou não de uma necessidade interior. Não se tratava de saber se a forma é 
pessoal, ou racional, se possui semelhança com outras formas existentes, se possui estilo, se corresponde ou não àquelas que são partilhadas pelos movimentos de arte contemporâneos, mas se é expressão de uma necessidade íntima do artista.

21 Líder espiritual do grupo, Wassily Kandinsky tinha, além da pintura, forte interesse pela música, poesia, religião e filosofia. Seguindo a tradição wagneriana de busca de uma arte total, tentava encontrar a base espiritual comum a todas as artes, caminho também seguido por Xul Solar. Nessa direção, os membros do grupo realizaram experiências que visavam a encontrar a equivalência entre o som e a cor, experiências transpostas pelo artista argentino na construção de seu piano cromático e na modificação da linguagem e da escala musical. Sua trajetória não parou aí : o artista iria dar maior amplitude a esta ambição ao cruzar os domínios artísticos com os conhecimentos provenientes do campo místico que o levaram a conceber suas criações a partir de considerações cosmológicas, contribuindo para isso especialmente a astrologia e a cabala.

Além de Wassily Kandinsky, foi grande admirador de Paul Klee. No seu retorno a Buenos Aires, em 1924, ele trouxe na bagagem três livros sobre o artista suíço. Na pintura, essa admiração atesta-se na proximidade havida entre os elementos que ambos utilizam em seus quadros. As setas, os números, as letras, os símbolos cosmológicos celestiais - sol, lua, estrelas - as formas geométricas - círculo, quadrado, triângulo, elipse - além de composições permeadas por faixas, são comuns em suas obras. Há suposições de que seria Paul Klee o artista a exercer maior influência sobre Xul Solar.

23 Se o expressionismo alemão o marcou, principalmente nos primeiros anos de sua estada na Europa, grande importância teria sua inserção no mundo místico, o qual determinou em parte sua concepção cosmológica de vida e os desdobramentos de suas iniciativas artísticas.

24 Em 1913, foi iniciado na doutrina da ordem Astrum Argentium, fundada pelo mago inglês Aleister Crowley, com quem iria se encontrar em 1924, dando início ao aprendizado de um método que emprega símbolos para propiciar visões. Xul Solar aplicou, por designação de Crowley, esse método aos sessenta e quatro hexagramas do I Ching, resultando num conjunto de visões místicas publicadas em neocrioulo com o título de San Signos. Segundo Daniel Nelson, essas visões representam uma chave incomensurável para interpretar a iconografia das pinturas do artista, "os seres e as paisagens representados em suas aquarelas são virtualmente idênticos aos que aparecem nos San Signos" (NELSON, 2005, p. 50).

Se o tratamento técnico aplicado por Xul Solar a sua pintura pode ser explicado em grande parte pelo conhecimento possuído à respeito dos movimentos artísticos mais avançados do período, em termos de conteúdo suas pinturas são totalmente vinculadas ao mundo místico e religioso. $\mathrm{O}$ artista frequentou cursos do fundador da antroposofia Rudolf Steiner trazendo em seu retorno a Buenos Aires inúmeros volumes de sua obra, além das de Helena Blavatsky, Edouard Schuré, Annie Besant, Leadbeater e Erich Bischoff, referências que ampliam a importância do misticismo na trajetória formativa do autor.

Xul Solar retorna a Buenos Aires em 1924 para reencontrar uma cidade mais dinâmica onde as contradições sociais passaram a ser cada vez mais projetadas e tratadas como expressão de contradições entre o habitante nativo e o estrangeiro. Na cena intelectual, essas contradições assumiram as formas de um confronto que tinha por foco a questão do nacionalismo e do cosmopolitismo na arte e na cultura, ligadas às forças que impulsionavam a modernidade Argentina. 

da hierarquia social, também retornavam de uma formação européia. Em dia com os últimos avanços no campo artístico, eles acirravam, através de revistas e periódicos o confronto. Esses veículos eram meios de difundir as novas ideias a respeito da arte, visando a criar um campo de receptividade para as suas obras. Os periódicos Proa (1921), Prisma (1921-22), Atlântida (1923-24) e Martín Fierro (1924-27) são representantes desse momento singular. articular artistas de diversos campos, visando a introduzir uma linha de inserção da arte moderna pautada na ideia de construção de uma nova identidade nacional estabelecida a partir do meio urbano.

A cidade, espaço privilegiado de constantes transformações, caracterizada pela aceleração de todos os tipos de fluxos e de misturas multiculturais, apresentava-se como o oposto do modo de vida tradicional do campo, com suas atividades lentas, nucleada pelas famílias, presas à terra e à atividade braçal e ao caudilhismo político, baluarte do nacionalismo conservador. Este dois polos representariam, respectivamente, no plano cultural, mas não só nele, as ideias de modernidade e tradição.

O modo como Xul Solar enfrentou esta problemática pode ser extraído de suas obras por meio das representações plásticas e das literárias. Nas pinturas dedicadas à exploração de diversas formas arquitetônicas podem ser encontradas várias representações que remetem aos dois polos temporais indexadores das posições conflitantes expressas no campo político e cultural: o passado e o futuro.

Dentre os exemplos mais significativos desta polarização tem-se, por um lado, uma série de construções arquitetônicas sem referências no passado, mas que parecem extrair do presente e projetar no futuro novas possibilidades de vida para o homem. Por outro lado, há construções que evocam um passado longínquo, formas arquitetônicas que remetem a uma época distinta e distante do passado argentino.

Dentre as formas arquitetônicas do primeiro grupo, a mais radical é Vuel Villa, aquarela sobre papel, produzida em 1936. Nela, o artista trama urbanização do espaço e dispositivos tecnológicos para projetar uma cidade aérea. Diversos mecanismos como motores, hélices e rodas, símbolos da modernização e da modernidade, são acoplados a plataformas móveis que sustentam casas e prédios para dar forma a uma cidade que se descola da terra e ocupa o plano aéreo, uma cidade flutuante, uma cidade apontando para um modo de vida futuro. Na perspectiva extraída de Vuel Villa, Xul Solar estaria delineando o afastamento a ser mantido pelo artista em relação aos dispositivos técnicosociais que engendram vínculos entre os homens com base na conjunção das ideias de nação e de território, se o projeto é conceber novas possibilidades de vida para o homem do porvir.

Se a arquitetura é um destes dispositivos e a cidade que Xul Solar vislumbra como possibilidade futura é uma cidade que voa, o amálgama a unir os homens deveria ser de outra natureza. Ao menos a ideia de nação não poderia estar mais ligada à de território. Essa cidade que voa poderia ser pensada como o espaço de uma nova sociabilidade nascida da confluência entre dispositivos técnicos e homens desterritorializados, cuja representação os imigrantes encarnariam.

34 Vuel Villa, cidade desterritorializada, constituída por homens que perderam os vínculos com seus territórios de origem e vivendo em conflito no território da pátria Argentina, se 
apresentaria não como uma etapa no desenvolvimento do Estado Nação, mas como o embrião de uma nação nômade e cósmica. Desenraizada, Vuel Villa seria verdadeiramente uma cidade cosmopolita. Visto a partir dessa perspectiva, poder-se-ia conjecturar que Xul Solar pensaria a questão da modernidade na Argentina vinculada a uma abertura para o universal, estando nas mãos dos artistas trabalharem nesse plano, explicitando-a, como ele mesmo fez, com a sua cidade voadora.

No outro grupo de imagens arquitetônicas, há a presença de cidades relacionadas a tradições muito antigas, representadas nas construções piramidais como em Pirâmide (1921) e em cidades místicas ou religiosas como em Proyecto (1918). Estas formas arquitetônicas estão ligadas ao passado, mas o revelado através delas está preso a um tempo longínquo, não é o passado que poderia ser encontrado ou redescoberto nas casas e nas vilas campesinas ou na antiga Buenos Aires. Ultrapassar o passado próximo e territorialmente determinado indo ao encontro de formas oriundas de passados remotos, especialmente do período pré-colombiano, é um procedimento posto em ação por Xul Solar para invalidar a ideia de trazer do passado argentino as formas arquitetônicas que simbolizariam uma forma de sociabilidade peculiar ao argentino, propiciando os fundamentos a um nacionalismo de tipo tradicional.

No plano literário, o artista enfrentou um desafio um tanto mais complexo. Nas décadas iniciais do século XX, a língua era parte central da construção da ideia de nação argentina. $\mathrm{O}$ nacionalismo expresso nesse período identificava no estrangeiro uma ameaça à integridade da língua. Esta categoria, mais do que se referir ao imigrante, identificava os não modelados ou não submetidos ao proposto nas escolas, sobretudo o bem falar e o bem escrever na língua castelhana, ou aqueles que não haviam incorporado as normas sociais imperantes. As falas que se faziam ouvir nas expressões de lutas políticas e sociais, onde o imigrante e seus descendentes eram os protagonistas, soavam como um perigo à integridade da nação e como uma ameaça à língua e à cultura. As falas misturadas das ruas, bares, cafés, lojas e armazéns eram vistas como o mais nítido sintoma da degradação da língua nacional.

As vertentes conservadoras da tradição nacionalista viam no dialeto do campo falado pelo gaúcho, um crioulo primitivo, a língua a ser alçada como representativa da nação argentina, ao passo que uma língua coloquial, também agauchada, falada nos subúrbios de Buenos Aires, motivaria as ações da vanguarda em direção à caracterização de uma língua nacional. $\mathrm{O}$ escritor Jorge Luis Borges faria desse caminho um meio para escapar à dupla armadilha que a questão da língua nacional reservava : recuperar uma língua arcaica ou submeter-se às regras ditadas pela Academia de La Lengua Espanôla. Jorge Luis Borges buscou encontrar na imbricação entre língua coloquial urbana, viva, e língua escrita uma maneira de se opor ao mesmo tempo às duras regras da academia espanhola e à recuperação de uma língua crioula arcaica. Porém, este procedimento iria também excluir o imigrante e suas misturas linguageiras; o crioulismo de Jorge Luis Borges não comportava os estrangeirismos na língua, sobretudo de origem italiana.

Se o problema de uma língua nacional foi pensado pelos conservadores como um foco de resistência às modificações provocadas pela presença de diversos idiomas falados pelo imigrante na cidade, querendo com isso se preservar e preservar a própria língua, operando por exclusão da diferença, não foi muito distinto o que foi feito pela vanguarda nacionalista. Xul Solar, porém, ocupa um lugar diferenciado no processo ; ao contrário dessas duas vertentes, ele partia justamente da efervescente mistura de línguas tão bem representadas na cidade de Buenos Aires, para inventar uma língua ampliando de um 
modo tal as possibilidades da língua crioula que a abria para o continente latinoamericano. Xul Solar chamou de neocrioulo esta sua invenção. Do mesmo modo, procurou desenvolver a panlíngua incorporando em sua construção, além do espanhol, do português do Brasil e do tupiguarani, as contribuições do inglês, do alemão e do francês, atribuindo-lhe um caráter universal. No plano da língua pode ser dito que o artista operava por inclusão, não lhe importava a ideia de uma língua livre de contaminações estrangeiras, mas sim a ideia de utilização das virtudes de cada língua particular para construir uma língua nova, capaz de possibilitar a comunicação entre o maior número de homens pertencentes a distintas nacionalidades. Percebia nas novas línguas possibilidades abertas e propiciadoras para a construção do homem do futuro. As línguas existentes não eram para ele coisas a serem recuperadas e preservadas, mas, como diria, coisas a serem melhoradas ou aperfeiçoadas. A vertente modernista que Xul Solar representou era, nesse aspecto, também cosmopolita.

39 A posição assumida em relação à questão do nacional e da língua na Argentina, além de evitar as armadilhas do conservadorismo político e cultural, tinha na ideia de construção de um novo homem a sua aposta no futuro, extraindo dela as consequências em termos de língua e linguagem. Se, como oportunamente será visto, a língua neocrioula destinararse-á ao homem latino-americano, este concebido como um tipo novo e a panlíngua como a língua pensada para possibilitar a comunicação entre os povos dos diversos blocos continentais com abrangência universal, Xul Solar concluirá que essas línguas necessitarão de uma nova linguagem para poderem ser expressas. É justamente neste ponto de confluência entre língua e linguagem que começará a desenvolver as pesquisas que o levarão à construção da linguagem plasti-útil, um novo tipo de dispositivo literopictural distinto do ponto de vista conceitual e técnico dos modos de expressão dominantes que vinculavam a palavra a e a imagem conhecidos sob as denominações de pintura verbal e poesia visual. Nisto reside a sua importante e pouco estudada contribuição para a história da pintura ocidental.

40 O que teria levado Xul Solar à invenção da linguagem plasti-útil? Estaria ela ligada exclusivamente a problemas concernentes ao campo artístico ou pretendia ele atingir através dela outras dimensões da experiência humana? E língua neocrioula e a panlíngua, qual relação teriam essas invenções com a linguagem plasti-útil e a que se destinam? 0 que diferencia uma língua da outra?

41 As respostas podem ser encontradas em diversas entrevistas concedidas, em textos escritos sobre Emilio Pettoruti, em conferências e artigos sobre a linguagem.

A língua neocrioula começa a ser desenvolvida antes da linguagem plasti-útil. Os primeiros indícios de sua criação aparecem nas cartas escritas da Europa à sua família nos primeiros anos de sua estadia, assim como em quadros datados de 1915. Por outro lado, as menções à linguagem plasti-útil e os quadros que esboçam um dos tipos de escritura que irão constituí-la começam a aparecer no final da década de 20.

Em entrevista concedida ao jornal La Nación em 20 de outubro de 1929, Xul Solar fala das suas invenções de linguagem e pela primeira vez vincula o neocrioulo a um novo sistema de escritura. Após comentar sobre a letra gótica julgando-a absurda, diz o entrevistador ter o artista lhe apresentado um documento onde "se extiende las más curiosa estenografia e lhe afirmado: estoy reformando la escritura [...] sin estas cifras no podríamos escribir la nueva lengua". A elas o entrevistador assim se refere: "ondulantes ganchos, quebradas geometrías, finos tentáculos. Aquello, desde luego, tiene un aspecto imaginativo e taquigráfico" (BARREDA, 2005, p. 63). 
Pela descrição, essas cifras são as que mais tarde virão a constituir o primeiro tipo de escritura a compor a linguagem plasti-útil denominado escritura cursivas.

Xul Solar não estava apenas reformando a escritura; o idioma era objeto de igual trabalho. Dizia ele na mesma entrevista que "el castellano se halla atrasado en varios siglos... Es un idioma de palavras demasiado largas, cacofónico..." (Idem, p.63), precisando ser melhorado. Em termos semelhantes também referiu-se ao idioma francês e ao italiano, evidenciando a necessidade de modificá-los. Ele partia dos problemas das línguas que conhecia não só para pensar os seus aperfeiçoamentos, mas para construir a nova língua, nomeando-a ao repórter de el neocriollo.

Observa-se na entrevista, que não só procurava desenvolver a língua neocrioula, mas buscava encontrar signos gráficos adequados para representá-la. Entretando, não explica porque sem as cifras não é possível escrever a nova língua, ou em que sentido esta é dependente da criação de um novo código. A resposta fica mais difícil de ser alcançada se for considerado que nos textos escritos nessa língua, como por exemplo, Poema (SOLAR, 2005, p. 161-164 e p.172-176.) e Visión Sobre El Trilíneo (SOLAR, 2005e, p. 168-171 e p. 181-184.), emprega o alfabeto ocidental. Por que um novo sistema de signos se é demonstrado que se pode escrever em neocrioulo com o atual sistema de escritura?

Embora não se encontre resposta para isso nas entrevistas concedidas e nos textos escritos, não pode ser desconsiderado que ele efetivamente buscava construir um novo tipo de escritura, ou mais precisamente, vários tipos de escrituras e que elas tinham relação com o neocrioulo e com a panlíngua. Resta tentar encontrar quais são essas relações ou vínculos.

Do visto até aqui se poderia considerar a linguagem plasti-útil como um sistema de signos feito para grafar a língua neocrioula, consideração que encontraria evidências nos seus quadros escrituras, onde essa língua é usada para transcrever ao pé da tela o codificado na linguagem plasti-útil. Mas pode ser aceita esta ideia plenamente? Pode a linguagem plasti-útil se prestar exclusivamente à representação do neocrioulo?

49 Xul Solar também fará referências à panlíngua que darão a entender ser com esta que a linguagem plasti-útil teria maior vínculo, retirando ao menos a exclusividade que poderia ser atribuída à língua neocrioula em relação à linguagem plasti-útil.

Primeiramente, cabe distinguir a língua neocrioula da panlíngua para ver se é possível esclarecer esta questão. Xul Solar refere-se à língua neocrioula e à panlíngua como entidades diferentes.

51 Diz o artista que a panlíngua é:

una lengua monosilábica, sin gramática, que se escribe tal como se pronuncia, de raíces básicas unívocas e invariables, combinables a voluntad, de fonética fácil, musical [...]. Cada consonante representa toda uma categoría de ideas calificadas por las vocales dispuestas en polaridad positiva e negativa [...] es regular; no tiene excepciones y es de acento evidente para que as palabras sean reconocibles (FOGLIA, 2005, p. 85).

2 Essas características são, segundo ele, as básicas em toda língua a priori. Além disso, a base de sua construção é astrológica e duodecimal.

O neocrioulo, por outro lado, é uma língua a posteriori, nascida da junção do português e do espanhol e mais tarde acrescida de termos da língua guarani e da língua inglesa, condicionada a um programa com vistas a tornar sua construção mais lógica e suas palavras mais sintéticas e sonoramente mais agradáveis. 
54 A língua neocrioula está baseada na palavra recolhida, selecionada e modificada de outras línguas; seu desenvolvimento está centrado na palavra. A pan-língua, por outra parte, baseia-se em monossílabas indicando palavras ou ideias, funcionando de maneira semelhante ao que se passa em termos de escritura nos sistemas ideogramáticos.

Xul Solar revela, através de alguns exemplos, como funciona a lógica construtiva das monossílabas da panlíngua :

La letra más dura, correspondiente a Saturno y que representa cantidad, que es como la ley de este mundo es la T. Ta significa cuanto; Ti, poco; Tu, mucho; Te, menos, y To, más. La Rr es la más movediza; corresponde a Sagitario, indicando verbos de acción: Rra, actuar; Rri, hacer o fabricar; Rru, deshacer; Rre, intercambiar, y Rro, moverse (Idem, ibidem, p. 85).

Essas diferenças são importantes, pois permitem evitar algumas confusões terminológicas que por vezes aparecem em trabalhos onde é abordada a questão da linguagem na obra do artista; não pode ser confundida a língua neocrioula com a panlíngua, uma não é sinônimo da outra.

o fato de os quadros escrituras aparecerem vertidos para o neocrioulo e o neocrioulo estar grafado em linguagem alfabética no limite inferior dos quadros significa, ao menos, que os signos da linguagem plasti-útil podem ser intercambiáveis com os da linguagem alfabética. Isso tem implicação direta sobre o vínculo entre um novo sistema de signos e língua neocrioula atribuído por Xul Solar. Se os signos da linguagem plasti-útil podem ser transcodificados para os do alfabeto latino, a linguagem plasti-útil pode servir para a expressão de qualquer idioma que emprega esse alfabeto. Nesse sentido, torna-se difícil compreender a existência de um vínculo especial entre a língua neocrioula e a linguagem plasti-útil ; por que seria ela mais adequada às expressões da língua neocrioula que às expressões da língua castelhana, da portuguesa, da guarani ou da inglesa, só para citar essas que são componentes da língua neocrioula?

A entrevista de 1929 ao jornal La Nación demonstra que no momento inicial do desenvolvimento da língua neocrioula e das primeiras grafias Xul Solar trabalhava no sentido de vinculá-las, porém, ao dedicar-se à panlíngua, ampliar as modalidades de signos e variar os tipos de escrituras, especialmente nos anos 50 e 60 , possivelmente tenha o artista abandonado essa ideia. É provável ter admitido a possibilidade de usar o mesmo sistema de signos para distintas operações de linguagem, eliminando a necessidade de um sistema para a língua neocrioula e outro para a panlíngua, como poderia ser aceito se consideradas as diferenças entre elas, especialmente se observada a correspondência entre a concepção da panlíngua e a lógica construtiva da linguagem plasti-útil.

Xul Solar concebe a panlíngua como um sistema monossilábico que permeia a construção dos signos da linguagem plasti-útil. Pensa a disposição das vogais a partir de inversões entre o positivo e o negativo, procedimento também adotado na configuração das grafias, não só em termos de vogais, mas das próprias consoantes. A acentuação evidente que almeja dar às palavras é facilitada pela lógica de acentuação da linguagem plasti-útil, estabelecida a partir da diferença de tamanho entre os signos que formam uma palavra ${ }^{1}$. Haveria, ainda, a perpassar as ligações entre essa língua e essa linguagem, os fundamentos astrológicos e numerológicos.

Sob a perspectiva da correspondência entre as lógicas da panlíngua e da linguagem plastiútil, poderia ser ponderado que ambas são quase a mesma coisa, sendo a primeira um sistema de signos gráficos correspondente às formas de expressão verbal da segunda. 
Porém, para essa consideração ser aceitável, as grafias monossilábicas da linguagem plasti-útil deveriam representar ideias e não meras sílabas de uma língua. Para melhor compreensão do problema, basta comparar o que ocorreria, por exemplo, com a monossílaba Ta se ela fosse representada em um dos tipos de escritura; a geométrica. Ta seria um quadrado com um triângulo no seu interior, na sua parte de baixo. Na panlíngua, foi visto acima, Ta significa quanto. Logo, seria de se concluir que, estando pintada num quadro, essa figura deveria ser compreendida como significando a palavra quanto e não simplesmente a sílaba $T a$. Isso, porém, não ocorre; tem-se sempre uma sílaba em linguagem plasti-útil, grafada em um dos seus tipos de escritura, cujo significado é o mesmo de uma sílaba no sistema alfabético. É essa a razão para julgar que há diferenças entre a panlíngua e a linguagem plasti-útil.

O mais curioso é que Xul Solar chamava a linguagem plasti-útil de formas pensamentos, subentendendo que seus signos monossilábicos deveriam expressar ideias; entretanto, ele usava essas formas para escrever apenas palavras.

Visto sob o aspecto da aplicação da linguagem plasti-útil, pode não haver razão para julgar que exista maior ou menor vínculo entre essa e a língua neocrioula ou entre ela e a panlíngua. Embora nascida de uma relação estreita com a panlíngua parece que a linguagem plasti-útil tornou-se autônoma.

Se até aqui foi privilegiada a distinção entre as línguas neocrioula, a panlíngua e a linguagem plasti-útil, tentar-se-á agora encontrar razões que possam justificar suas criações.

Xul Solar também diferencia a língua neocrioula e a panlíngua em função de contextos geopolíticos. Delimita o âmbito de abrangência da língua neocrioula à América Latina. Diz, em entrevista concedida à Héctor N. Indart, publicada em 1947 no número 1 da revista Él : "soy o creador del neo-criollo, lengua que reclama el mundo de latinoamérica "(INDART, 2005, p. 70) e repete essa afirmação com maior ênfase em 1951 para Gregory Sheerwood: "soy, y esto es lo que más me interessa momentáneamente - além de la exposición de pintura que estoy preparando - el creador de una lengua que reclama con insistencia el mundo de latinoamérica" (SHEERWOOD, 2005, p. 76).

Na mesma entrevista, ao fazer um comentário sobre a configuração da política global, diferencia o neocrioulo do que ele chamara de panlíngua. Diz :

estamos viviendo la época de los grandes bloques: Panamérica, Panaeuropa, Panasia [...]. El "criol" o "neocriollo" podría ser el idioma auxiliar de Panamérica ; la "panlingua" sería la lengua complementaria entre los tres bloques. La "panlingua" es notablemente sencilla y de grafia parecida a la esteno o taquigrafia (SHEERWOOD, 2005, p. 76).

Xul Solar via estas duas línguas como auxiliares na comunicação entre os povos, como um meio de favorecê-la ; a língua neocrioula para propiciar a comunicação entre os povos da América e a panlíngua entre os povos do planeta, mas não se encerravam no simples ato comunicativo os objetivos que pretendia com essas duas invenções. Ao se referir mais uma vez ao neocrioulo, justifica o seu uso como uma forma de consolidar o mútuo respeito, a confraternização e a convivência entre os países da América, sobretudo a Latina, que naqueles anos do pós guerra era um grande exemplo dado ao mundo convulsionado. Dizia : "qué mejor para consolidar esta tendencia de nuevo concepto de efeticva buena vencidad que un idioma comun compuesto por palavras, sílabas, raíces sacadas de las dos lenguas dominantes en centro y sudamérica : castellano y portugués" (SHEERWOOD, 2005, p. 76). 
67 Duas outras justificativas podem ainda ser encontradas para a invenção dessas línguas e também para a linguagem plasti-útil. Em artigo sobre o pintor e amigo Pettoruti, escrito não datado, provavelmente feito entre 1923 e 1924, Xul Solar assume um posicionamento político cultural de enfrentamento e de ruptura com a tradição europeia e com as amarras provenientes do passado colonial que imperou na América. Ele vê na arte o caminho e no neocrioulo o tipo capaz de levar esse intuito adiante. Neste sentido assim expressa:

somos y nos sentimos nuevos, a nuestra meta nueva no conducen caminos viejos y ajenos. Diferenciémonos. Somos mayores de edad y aún no hemos terminado las guerras pro independencia. Acabe ya la tutela moral de Europa. [...] Veamos claro lo urgente que es romper las cadenas invisibles (las mas fuertes son) que en tantos campos nos tienen aún como COLONIA, a la gran AMÉRICA IBÉRICA con 90 millones de habitantes. [...] neocriollo, un tipo de los futuros que ultrapassarán a la Europa (SOLAR, 2005c, p. 99, grifos do autor).

68 Xul Solar se insurge contra a arte europeia, embora não a negue completamente. Antes mesmo da antropofagia proposta no Brasil por Oswald de Andrade em 1928, já referia-se ao tipo de relação possível com a arte do velho continente em termos de metáfora digestiva: "asimilemos sí, lo digerible" (SOLAR, 2005c, p. 99). Para ele trata-se de concluir a independência espiritual da América pela força do novo que germina no artista crioulo, mescla parda do branco, do vermelho e do negro, ávido de criação: "admitamos, pues, que entre nosostros estàn ya - todavia ocultos en mayor parte - tantos o todo los gérmenes de nuestro arte futuro, y no en museos extranos, no en casa de célebres marchands ultramarino" (SOLAR, 2005d, p. 111).

69 A luta contra a cultura europeia torna-se, antes de tudo, na perspectiva da América, a luta por afirmar a sua pura diferença em relação à arte que se faz na Europa. Pois, como diz Xul Solar de si e dos artistas do continente americano, "somos una raça esteta, con el arte [...] empezaremos a decir lo nuevo nuestro" (SOLAR, 2005c, p. 99). E, diria ele, com uma outra língua, o neocrioulo.

70 A segunda justificativa para as sua invenções linguísticas ultrapassa o caráter regional associado à língua neocrioula, assumindo as conotações universais encontradas na panlíngua e na linguagem plasti-útil.

71 Em 18 de setembro de 1953, passados praticamente três décadas dos escritos sobre Pettoruti, onde aparece de maneira acentuada a oposição Europa/América, na entrevista concedida a Carlos A. Foglia, Xul Solar falou de suas invenções: o panxadrez, a modificação do teclado do piano, a panlíngua e o teatro de títeres e considerou o seu trabalho como sendo o de estabelecer as bases de uma cultura única. Disse:

Mi deseo, que involucra todas mis aspiraciones, es el de llegar a ordenar los instrumentos de uma cultura única, tomando siempre por base la astrología, en el sentido que podríamos llamar de cábala y facilitar el estudio de las artes para tornalas accesibles a todas las personas en sentido creador (FOGLIA, 2005, p. 86).

Sob as bases da astrologia e da numerologia presentes na cabala, pensa encontrar um fundo comum capaz de articular as diversas culturas particulares, razão pela qual buscou edificar a panlíngua e a linguagem plasti-útil tendo por referência os dois sistemas.

Tanto a panlíngua, quanto a linguagem plasti-útil se destinavam a auxiliar a comunicação entre as nações e os diversos povos, fato que, segundo o seu entendimento, contribuiria para melhorar a vida humana. Era isso que esperava de suas criações: "Siempre mis iniciativas tienen finalidad cultural. En mi calidad de ciudadano del mundo sueño con una 
vida mejor que nos acerque y nos torne más felices a todos los hombres del mundo, sin distinción de credos ni de razas" (Idem, ibidem, p. 87).

Em apresentação feita de si mesmo, Xul Solar dizia que vinha se dedicando muito "al problema de una lengua internacional posible por ahora, y de otra, a priori, que quiere ser perfecta" (SOLAR, 2005f, p. 57). Buscava construir uma língua perfeita, considerando, como faria Umberto Eco (ECO, 1994, p. 24), que esta procura só é feita porque se julga a língua imperfeita. "Alguna vez a de chegar la hora de criticar en buena fe, y de corrigir los defectos y fallas de nuestro idioma", afirmava ao iniciar a sua importante conferência sobre a língua realizada em 1962 no Archivo General de la Nación, para propor em seguida um programa mínimo de melhoras (SOLAR, 2005a, p. 198).

Poliglota ${ }^{2}$, conhecia as imperfeições e as virtudes de várias línguas, bem como, havia "estudiado el problema de diversas escrituras o grafías desde los puntos de vista lógico y plástico, además del práctico" (SOLAR, 2005f, p.57).

76 A tarefa de criar uma língua internacional auxiliar, proposta como um de seus objetivos, foi tentada por muitos outros homens. Umberto Eco diz que Couturat e Leau registraram, somente no decorrer do século XIX, trinta e oito sistemas de línguas internacionais, caracterizando o que ele chamou de "uma nova babel das línguas internacionais" (ECO, 1994, p. 360). Dentre os mais conhecidos desses sistemas estão o volapük e o esperanto.

Esta não é obra simples de ser realizada e pode-se duvidar da capacidade de um único homem para efetuá-la e Xul Solar sabia disso, porém, julgava que seria mais fácil "sobretudo para qualquiera que anduvo entre varias lenguas, apreciando y confrontando sus virtudes y defectos y que ha chocado con su razón y paciencia contra lo ilógico de los usos y costumbres en su propria lengua" (SOLAR, 2005a, p. 199). Dedicou grande parte de sua vida a esse projeto e trabalhava no desenvolvimento da linguagem plasti-útil quando morreu em 9 de abril de 1963, deixando em segredo o seu código e a outros a tarefa de decifrá-lo, o que já foi realizado ${ }^{3}$. Resta agora o desafio de aprimorar e desenvolver novos signos para a linguagem plasti-útil, aumentando com isso a sua versatilidade plástica.

Xul Solar construiu um sistema de linguagem complexo que envolve o signo verbal, a representação pictórica e a representação sonora, instaurando no domínio das relações entre o literário e o pictórico um novo espaço para a criação plástica. Em uma parte significativa de sua obra, que compreende o período dos anos 20 até o final dos anos 50, imperou o jogo com os efeitos de sentido que a palavra provoca ao estar em uma tela, em íntima relação com a imagem, permanecendo o artista no interior do que foi convencionado chamar de pintura verbal. Nesse aspecto Xul Solar manteve-se vinculado a uma tradição inaugurada por Georges Braque e Plabo Picasso.

79 A grande ruptura em relação a essa tradição deu-se com a utilização da linguagem plastiútil na pintura, com a qual, segundo ele, "se pode fazer quadros de formas infinitas, legíveis" (SOLAR, 2005b, p. 94).

Em artistas como Paul Klee, Joaquin Torres Garcia, Antoni Tàpies e Frédéric Bruly Bouabré, encontramos obras onde a palavra é tratada como um problema de linguagem e não como simples jogo com a imagem. Nos três primeiros insinua-se que ela está velada sob códigos primitivos, no último ela motiva a construção de um novo alfabeto.

81 É de ser observado que, se a palavra insinua-se num código, o moderno nos quadros dos três artistas é a revelação de que no código está contido o segredo ancestral da palavra ; a palavra é um segredo de escritura. Ao fato de a palavra estar presente ou não nos quadros desses artistas, pouca importância deve ser dada porque, em todo caso, a escritura a 
supõe. Esta via que liga Paul Klee, Joaquin Torres Garcia e Antoni Tàpies, caracterizada pela recorrência ou simulação de códigos arcaicos, de escrituras primitivas para sugerir a presença do verbo em suas telas, representa um tipo de corte com a tradição da pintura verbal, definido como aquele que indica o desaparecimento da visibilidade da palavra na pintura.

Ao ser transformada num problema de linguagem, remetida a um segredo de escritura, a palavra escrita se revela naquilo que é : um registro verbal em código. Só é vista a palavra na pintura porque ela está inscrita ou registrada num código conhecido. Sem esta condição não se pode ver a palavra, vale dizer : ler.

Pode ser dito que esta modalidade de tratamento plástico empregada por estes artistas implica o surgimento de uma nova categoria a ser estabelecida. Originada da trama que liga de maneira explícita a palavra e a imagem na pintura, num jogo que remete uma à outra, a nova forma tenderia a fundir a palavra na imagem. Não mais as palavras e as imagens, mas imagens/palavras é que passariam a ocupar a tela.

Xul Solar percebeu claramente este caminho e produziu uma radical ruptura conceitual. A relação palavra/imagem foi um campo de investimento construtivo que contagiou o meio literário e pictural na modernidade; a inovação artística passava pelos modos de articulação e de combinação entre o verbo e a plasticidade. Para o poeta, a palavra virou a matéria prima de uma composição plástica, o substrato que deveria, no limite, tornar-se pura forma. Para o pintor, a palavra passou a ocupar o espaço da tela, chegando ao ponto de ser ela mesma o único elemento da composição, reproduzindo no quadro a imagem de uma escritura.

Seguindo este impulso criador, Xul Solar não se contentou com a inserção de palavras na tela junto a imagens, como na primeira fase de sua obra, nem com obras compostas com signos que remontam a grafias antigas, como bem sugere o título de alguns de seus quadros. Seu projeto estético foi mais audacioso, quis compor quadros-escrituras com um sistema de signos que ele próprio inventou. É possível afirmar que se encontra na sua obra os modos dominantes de relação palavra/imagem que foram praticados por artistas a ele contemporâneos reafirmando a sua sintonia com as transformações ocorridas na pintura e na poesia ocidental, especialmente entre os anos 20 e 50. Porém, ao desenvolver seis conjuntos de signos ou tipos de escrituras compondo com eles uma linguagem que denominou pensi-formes ou linguagem plasti-útil e aplicá-la em seus derradeiros quadros, o artista ultrapassou, em torno da relação palavra/imagem, o que vinha sendo feito por seus contemporâneos. E, salvo o trabalho de Frédéric Bruly Bouabré, sua iniciativa continua ímpar nos dias atuais.

Nisso está justamente sua diferença e originalidade, ele apresenta em sua forma concentrada um novo dispositivo literopictural correspondente ao conjunto de respostas elaboradas para as questões que o atravessaram ao percorrer, ao longo de décadas, o campo artístico e cultural de paisagens latino-americanas e européias. Queria ele expor, através de formas, as ideias, os pensamentos.

Há que escutar atentamente o que disse: "Somos una raça esteta, con el arte [...] empezaremos a decir lo nuevo nuestro" (SOLAR, 2005c, p. 99). Suas palavras, embora distantes, acentuam a importância de ser observado o que fizeram e estão fazendo os artistas do novo mundo. É preciso investigar com mais rigor suas obras, oportunizando, no âmbito dos estudos comparados, avaliar as contribuições diferenciais que estariam sendo dadas para possibilitar a reconfiguração interpretativa do campo artístico 
contemporâneo. Para isso é necessário operar por descentramentos e sobrepor ao mapa geopolítico um outro de natureza geoestético.

A pintura tem em sua história grandes criadores; Xul Solar é um deles. Há de chegar, no espaço da crítica, o momento em que será amplamente estudado e reconhecido.

WAT Pierre, Littérature et peinture dans Le projet romantique, in Littérature et peinture. Europe, 2007, p. $107-121$.

\section{BIBLIOGRAFIA}

ABós Álvaro, Xul Solar. Pintor Del Misterio, 1a. Ed. Buenos Aires, Sudamericana, 2004.

ALCALÁ May Lorenzo, La Utopia Latinoamericana: Xul Solar, Matta y Lam, Buenos Aires, Fundacion Pan Klub - Museo Xul Solar, 1999.

ARGENTINA SITIOSJURIDICOS Constitución Nacional Argentina 1853 y reformas. Disponível em http:// www.biblioteca.jus.gov.ar/co... - Acesso : 23/01/2014.

ARTUNDO P. M., Xul Solar: una imagen pública posible, in Xul Solar: entrevistas, artículos y textos inéditos, 1. ed. Buenos Aires, Corregidor, 2005. p. 7-54.

ARTUNDO P. M., Papeis de trabalho.Introdução a uma exposição retrospectiva de Xul Solar. In PINACOTECA do Estado de São Paulo. Xul Solar. Visões e Revelações, São Paulo, Pinacoteca do Estado de São Paulo, 2005. p. 49-58.

BARREDA E. M., Por los reinos de la Cábala. (La Nación. Buenos Aires, 20 de octubre de 1929. Reproducciones : Una ninfa, Marina y Retrato fotográfico del artista), in Xul Solar : entrevistas, artículos y textos inéditos, ARTUNDO, P. M. (Org.), Buenos Aires, Corregidor, 2005. p. 61-66. BAUMgatner, M., "Paul Klee y Xul Solar - un encuentro: el artista como visionario", in Paul Klee invita à Xul Solar, MUSEO Nacional de Bellas Artes, Buenos Aires, Gaglianone, 1999, p. 29. BENDINGER Maria Cecilia G., Grafias Plastiutiles de Xul Solar, Editor: Elena Montero Lacasa de Povarché, Avallaneda, Fundacion Pan Klub, Museo Xul Solar, 2004.

BERGEZ Daniel, Littérature et Peinture, Paris, Armand Colin, 2004.

BRETON André, Le surréalisme et la peinture, Paris, Gallimard, Folio, 1965.

BORGES Jorge-Luis, “Hommage a Xul Solar”, in Musée D’Art Moderne de la Ville de Paris-20 octobre-27 novembre 1977.

CANCLINI Néstor García, "Notícias recientes sobre la hibridación", in Artelatina. Org. Heloisa Buarque de Hollanda, Beatriz Resende. Rio de Janeiro, Aeroplano Editora, 2000, p. 60 - 80. CRISTIÁ Cintia, "Xul Solar e a música: a reunião das artes", in Xul Solar. Visões e Revelações, São Paulo, Pinacoteca do Estado de São Paulo, 24 de setembro a 30 de dezembro de 2005, p. 61 - 68. DAVVETAS Démosthènes, Ecriture poétique \& Langage plastique, Antoni Tàpies, Tome 2, Trad. Karine Coressis. Paris : Au Même Titre, 2000. 
DAVVETAS Démosthènes, Ecriture poétique \& Langage plastique, Cy Towmbly, Tome 3, Trad. Karine Coressis, Paris, Au Même Titre, 2000.

DELEUZE Gilles, Lógica do sentido, Trad. De Luiz Roberto Salinas Fortes, São Paulo, PERSPECTIVA, 1974. DELEUZE Gilles, Proust e os signos, Trad. Antonio Carlos Piquet, Roberto Machado. Rio de Janeiro, Forense-Universitária, 1987.

ECO Umberto, La recherche de la langue parfaite dans la culture européenne, Paris, Seuil, 1994.

FoGLIA C. A., Xul Solar, pintor de símbolos efetivos. (El hogar, Buenos Aires, no 2288, p.49-51, set. 1957), in Xul Solar : entrevistas, artículos y textos inéditos, ARTUNDO, P. M. (Org.), Buenos Aires, Corregidor, 2005, p. 80-87.

GERHEIM Fernando, Linguagens inventadas: palavras, imagens, objetos: formas de contágio, Rio de Janeiro, Jorge Zahar, 2008.

GRADOWCZYK Mario H., Alejandro Xul Solar, Buenos Aires, Ediciones Alba, Fundación Bunge y Born, 1994.

GRADOWCZYK Mario H., Xul Solar, Buenos Aires, Anzilotte, 1988.

HABKOST N. M., Entre peinture et langue: l'invention d'un langage dans l'œuvre de Xul solar, thèse (doctorat en sciences du langage), EHESS, paris, 2009.

HABKоST N. M., "L'inter-relation entre peinture et littérature dans l'œuvre plastico-poétique de Xul Solar", in Art et Littérature d'Amérique Latine, prg. Alejandro Canseco-Jerez. Centre d'Étude des Textes et Traductions. Université Paul Verlaine, Metz, 2006, p. 109 - 120.

INDART H. N., "Xul Solar, creador del panajedrez. (Él. Revista mensual ilustrada para el hombre y el hogar", Buenos Aires, a. 1, n. 1, enero de 1947, [s.p.]), in Xul Solar: entrevistas, artículos y textos inéditos, ARTUNDO, P. M. (Org.), Buenos Aires, Corregidor, 2005. p. 70-72.

JELINEK Elfriede, Littérature et peinture, Europe, 2007.

KANDINSKY Wassily, Regards sur le passé et autres textes 1912 - 1922, Édit. Jean-Paul Bouillon. Paris, Hermann, 2003.

KERN Maria Lúcia Bastos, "O campo da arte em Buenos Aires: debates e práticas artísticas", in Xul Solar. Visões e Revelações, São Paulo, Pinacoteca do Estado de São Paulo, 24 de setembro a 30 de dezembro de 2005, p. 71-78.

KLEE Paul. Théorie de l'art moderne, Trad. Pierre-Henri Gonthier, Saint- Amand, Folio. 2005.

LANEYRIE-DAGEN, Nadeije, “Lire la peinture ?”, in Revue littéraire mensuelle Europe, Org. Charles Dobzynski. Paris, Europe, 2007, p. 227-246.

LANGEIRA Jacinto (org.), Du mot à l'image \& Du son au mot. Théories, Manifestes, Documents, une anthologie de 1897 à 2005, Marseille, Le Mot et Le Reste, 2006.

LORENZO ALCALÁ May, La utopía lationoamericana: Xul Solar, Matta y Lam, Buenos aires, fundación pan klub - museo xul solar, 1999.

NELSON D. E., Os San Signos de Xul Solar: O livro das mutações, in Xul Solar. Visões e Revelações, PINACOTECA do Estado de São Paulo, São Paulo, Pinacoteca do Estado de São Paulo, 2005. p. 49-58.

OLENDER Maurice, Les langues du paradis, Paris, Seuil, 1989.

oUAKNIN Marc-Alain. Les mystères de l'alphabet, Paris, Assouline, 1997. 
Paul Klee invita à Xul Solar, Museo Nacional de Bellas Artes, Buenos Aires, Gaglianone, 1999. Textos de Jorge GLUSBERG, Michael BAUMgarTnEr y Jorge LOPES ANAYA

PERROT Raymond, De la narrativité en peinture. Essai sur la Figuration Narrative et sur la figuration en général, Paris, L'Harmattan, 2005.

PRAZ Mario, Mnemosina: paralelo entre la literatura y las artes visuales, Caracas, Monte Ávila, s/d.

RAMIREZ Mari Carmen, "Identidad o legitimación? Apuntes sobre la globalización y El arte en América Latina" in Artelatina, Org. Heloisa BUARQUe DE HolLANDA, Beatriz RESENDE, Rio de Janeiro, Aeroplano Editora, 2000, p.11-34.

SARLo Beatriz, "Conflito e representações culturais", in Revista Novos estudos - CEBRAP. São Paulo, CEBRAP, No 75, julho 2006, p.81-91

SARLo Beatriz, Una modernidad periférica: Buenos Aires 1920 y 1930, Buenos Aires, Edições Nueva Visión, 1988.

SHEERWOOD G., "Gente de mi ciudad: Xul Solar, compeón mundial de panajedrez y el inquieto creador de la "panlingua", (Mundo Argentino. Buenos Aires, 10 de agosto de 1951, p. 14), in Xul Solar: entrevistas, artículos y textos inéditos, ARTUNDO P. M. (Org.), Buenos Aires, Corregidor, 2005. p. 75- 80.

SOLAR A. Xul, "Conferencia sobre lengua ofrecida por Xul Solar en el Archivo General de la Nación", in Xul Solar: entrevistas, artículos y textos inéditos ARTUNDO P. M. (Org.), 1. ed. Buenos Aires, Corregidor, 2005a., p.198-204.

SOLAR A. Xul, Apuntes de neocriollo, Azul. Revista de Ciencias y Letras. Azul, a. 2, n. 11, agosto 1931, p. 201-205, in Entrevistas, artículos y textos inéditos, Org. Patricia M. ARTUNDO, 1a. Ed. Buenos Aires, Corregidor, 2005, p. 164-168 et p. 176-181.

SOlAR A. Xul, "Nota de redacción: Xul Solar, el hombre increíble" (El Mundo. Buenos Aires, viernes 20 de octubre de 1961) in Xul Solar: entrevistas, artículos y textos inéditos, ARTUNDO, P. M. (Org.), 1. ed. Buenos Aires, Corregidor, 2005b, p. 93-95.

SOLAR A. Xul, "P e t t o r u t i" (Texto sin datar [1923 - 1924]; Archivo Documental. Fundación Pan Klub - Museo Xul Solar), in Xul Solar: entrevistas, artículos y textos inéditos, ARTUNDO, P. M. (Org.), 1. ed. Buenos Aires? Corregidor, 2005c. p. 98-104.

SOLAR A. Xul, "Pettoruti" (Martín Fierro. Periódico quincenal de arte y crítica libre. Buenos Aires, segunda época, a. 1, n. 10-11, septiembre-octubre de 1924, [p.1, 7y 8]), in Xul Solar: entrevistas, artículos y textos inéditos, ARTUNDO P. M. (Org.).1. ed., Buenos Aires, Corregidor, 2005d. p. 107-111. SOLAR A. Xul, "Visión sobre el trilíneo" (Destiempo. Buenos Aires, a. 1, n. 2, noviembre de 1963, p. 4), in Xul Solar: entrevistas, artículos y textos inéditos, ARTUNDO P. M. (Org.). 1. ed. Buenos Aires, Corregidor, 2005e. p. 168-171 e p. 181-184.

SOLAR A. Xul, "Poema. Imán", Paris, abril 1931, p. 50-51 Reproducido con variantes en Signo. Buenos Aires, n. 3, [abril] 1933, p. 3-5, in Entrevistas, artículos y textos inéditos, Org. Patricia M. ARTUNDo, 1a. Ed. Buenos Aires, Corregidor, 2005. Pg. 161-164 e pg.172-176.

SOLAR A. Xul, "Xul Solar" (Autógrafo en tinta negra, sin datar [1962 ?]. Archivo Documental. Fundación Pan Klub - Museo Xul Solar), in Xul Solar: entrevistas, artículos y textos inéditos, ARTUNDO, P. M. (Org.), 1. ed. Buenos Aires, Corregidor, 2005f, p. 56-57.

SOURIAU Étienne, La Correspondance des Arts. Éléments d'Esthétique Comparée, Paris, Flammarion, 1947. 


\section{NOTAS}

1. Ver especialmente o capítulo "Le mot : entre le son e l'image" (HABKOST, 2009).

2. O interesse de Xul Solar pela invenção de línguas pode ser compreendido desde sua formação inicial no interior do núcleo familiar, que o levou a dominar os dialetos falados por sua mãe de descendência italiana e a língua alemã falada por seu pai, passando pela língua inglesa e a francesa aprendidas na escola e, além de sua língua nacional, o castelhano, falava o português e o guarani. Segundo depoimentos, o artista conhecia bem o grego, o latim, o chinês, o sânscrito e o russo.

3. A decodificação dos sistemas de escrituras que compõem a linguagem plásti-útil foi realizada em tese de doutorado defendida no Centre de Recherche Sur Les Arts Et Le Langage, na EHESS, em Paris. Ver Habkost (2009).

\section{RESUMOS}

Trata o artigo da criação de uma linguagem literopictural de autoria do artista argentino Xul Solar. Denominada de plásti-útil, apresenta-se como um sistema complexo que envolve o signo verbal, a representação pictórica e a representação sonora, instaurando no domínio das relações entre o literário e o pictórico um novo dispositivo de produção plástica. Desenvolvida em meio a trama da criação de duas novas línguas, o neocrioulo e a panlínguas, esta linguagem é pensada como as novas cifras necessárias para exprimí-las. Define a posição do artista em torno do debate entre tradição e modernidade na Argentina nas primeiras décadas do século XX e situa a originalidade de sua obra em contraste ao que vinha sendo feito na pintura européia, particularmente no âmbito da pintura verbal no mesmo período.

L'article traite de la création d'un langage littéraire et pictural, créé par l'artiste argentin Xul Solar. Appelé "plásti-útil », il se présente comme un système complexe qui implique le signe verbal, la représentation picturale et la représentation sonore, mettant en place, dans les rapports entre littérature et peinture, un nouveau dispositif de production plastique. Développé dans la cadre de la création de deux nouvelles langues, le «néo-créole » et la " pan lengua », ce langage est pensé comme un nouveau code permettant de les exprimer. Il situe l'artiste dans les débats entre « tradition et modernité » dans l'Argentine des premières décennies du XXe siècle et signale l'originalité de son oeuvre par rapport à la peinture européenne, particulièrement dans le cadre de la peinture verbale de la même période.

\section{ÍNDICE}

Mots-clés: Xul Solar, art moderne, peinture et langage, peinture verbale Palavras-chave: Xul Solar, arte moderno, pintura e linguagem, pintura verbal 


\section{AUTOR}

NESTOR M. HABKOST

Professor Associado II e Diretor do Centro de Ciências da Educação na Universidade Federal de Santa Catarina. Doutor em Ciências da Linguagem pela École des Hautes Études en Sciences Sociales e pesquisador associado da Equipe Fonctions Imaginaires et Sociales des Arts et des Littératures (EHESS).

Email: habkost[at]yahoo.fr 